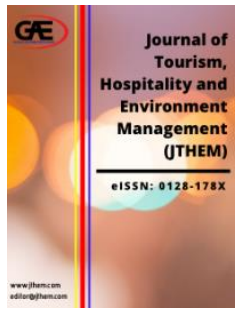

\author{
JOURNAL OF TOURISM, \\ HOSPITALITY AND \\ ENVIRONMENT MANAGEMENT \\ (JTHEM) \\ www.jthem.com
}

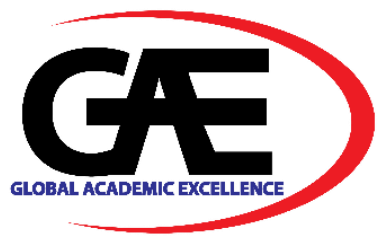

\title{
DO WORK ENVIRONMENT, INDIVIDUAL FACTOR AND TRAINING PROCESS INFLUENCE THE EFFECTIVENESS OF TRAINING PROGRAM FOR HUMAN RESOURCE IN THE HOTEL SECTOR?
}

\author{
Nurhazani Mohd Shariff $^{1 *}$, Azlan Zainol Abidin ${ }^{2}$, Asif Zamri Zainol ${ }^{3}$, Johan Abdullah ${ }^{4}$ \\ 1 School of Tourism, Hospitality \& Event Management, Universiti Utara Malaysia, Malaysia \\ Email: hazani@uum.edu.my \\ 2 Tunku Puteri Intan Safinaz School of Accountancy, Universiti Utara Malaysia, Malaysia \\ Email: azlan@uum.edu.my \\ 3 Overview Sdn. Bhd., Malaysia \\ Email: overviewsb@gmail.com \\ 4 The Datai Langkawi, Kedah, Malaysia \\ Email: hrm@dataihotels.com \\ Corresponding Author
}

\section{Article Info:}

Article history:

Received date: 07.02.2021

Revised date: 05.03.2021

Accepted date: 12.03.2021

Published date: 15.03.2021

\section{To cite this document:}

Mohd Shariff, N., Zainol Abidin, A., Zainol, A. Z., \& Abdullah, J. (2021). Do Work Environment, Individual Factor And Training Process Influence The Effectiveness Of Training Program For Human Resource In The Hotel Sector? Journal of Tourism, Hospitality and Environment Management, 6 (22), 5064.
Abstract:

As a service-oriented industry, human resource plays a vital role in the hotel sector. Hotels need to provide efficient training to guarantee the human resource performs quality work which satisfies the customers. To improve training among employees and prevent changes in employees' behaviour, the hotel sector needs to acknowledge the factors that impact the training effectiveness. This study was conducted to investigate the influence of work environment, individual factors, and training process on the effectiveness of human resource training programs in the hotel sector. Using The Datai Langkawi is a highly well-known resort in Malaysia, the study surveyed 45 employees who have attended the training program by distributing a questionnaire which is adopted and adapted from the Kirkpatrick and Kirkpatrick (2007) four levels of the evaluation training model. Three major hypotheses are developed and tested using regression analysis. The study indicates that all three factors significantly influenced the effectiveness of the training program in the hotel sector. Four variables in the work environment are found to be significant factors that influenced the effectiveness of the training program which are social support, opportunity to perform, reward system, and organizational culture. Similarly, the three variables in the individual factor which are ability, attitude, and motivation also derived as significant factors influencing the effectiveness of the training program. However, it is noted in the study that only training design derived as a 


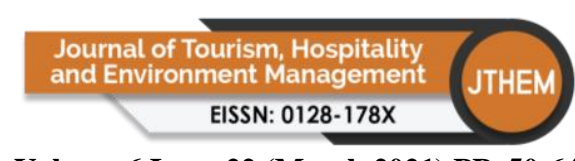

Volume 6 Issue 22 (March 2021) PP. 50-64

DOI 10/35631/JTHEM.622006

DOI: $10.35631 /$ JTHEM.622006.

This work is licensed under $\mathrm{CC}$ BY 4.0 ()(1) significant factor influenced the effectiveness of the training program whilst training needs to be shown insignificant result as a factor influencing the effectiveness of training program in the hotel sector. The findings of the study, in conclusion, shows the importance for the hotel management to take into account the significant factors influencing the training program as they may lead as a motivator to the human resources of the hotel sector in performing their tasks.

Keywords:

Human Resource, Training Program, Work Environment, Individual Factor, Training Process, Hotel Sector, The Datai Langkawi

\section{Introduction}

As the key asset in organizational survival particularly to the training and development decisions, human resource is seen as a vital component in the hospitality operation (Atieno, 2015). The hotel sector especially relies on its human resources, hence it needs the involvement of staff from all departments to operate smoothly. Operated as a service intensive sector, hotels must prioritize in training and it is essential for the hotel sector to come out with an effective training program for its human resources. Training is considered as a core human resource development strategy taken up by hotels in an attempt to improve their staff and the overall hotel performance. According to Punia and Kant (2013), a key to obtaining consistent success with training programs is to have a systematic approach to measurement and evaluation. It offers advantages including the improvement of productivity and the achievement of sustainable competitive advantage. Amritharaj and Vembar (2014) believe that the hotel sector needs to train employees as it can help to improve customer service quality through employees' management skills, social skills, language, ethics and attitudinal skills and expertise in the subject knowledge.

In a study conducted by Do (2013), it was highlighted that to operate in an ever-changing and highly competitive environment, it is a must for the organizations in the hospitality industry to constantly provide adequate training for their staff. Training plays a key role in ensuring that the staff is equipped with skills and knowledge required to deliver good customer services. In fact, these new learning experiences are believed to increase the staff motivation for learning, which is one of the main issues that the training professionals at the company find difficult to deal with. Several studies have indicated the importance of having effective training program for hotel employees to gain competitiveness (Chan Kim Lian, Che Sha'ari, \& Dasan, 2017; Chaturvedi, 2016; Dardeer, 2018; Masfar, 2020; Mhlanga, 2018; Mohd Shariff \& AlMakhadmah, 2012). Like any other human resource management function, training can be very wasteful if not cautiously planned, designed and implemented within all firms. Even though great investments are spent every year on the initiation and preparation of training programs for the purpose of improving knowledge and skills and for gaining competitive edge, a mere $10 \%$ of the knowledge and skills acquired from training are made use of by employees on the actual job and employees fail to effectively apply their skills in training on their work environment (Baldwin \& Ford, 1988; Clemenz, 2001).

This existing gap between the training programs content and the application to actual tasks can be attributable to several reasons which can be divided into three main categories: work 


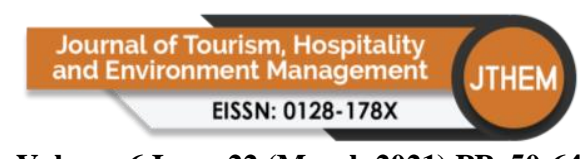

Volume 6 Issue 22 (March 2021) PP. 50-64 DOI 10/35631/JTHEM.622006

environment (Amritharaj \& Vembar, 2014; Dardeer, 2018), individual factors (Chan Kim Lian, Che Sha' ari \& Dasan, 2017; Mhlanga, 2018), and the training process (Baldwin \& Ford, 1988; Chan Kim Lian, Che Sha'ari \& Dasan, 2017; Mohd Shariff \& AlMakhadmah, 2012; Noe, 2010). Failure to transform training investments into significant improvements in on the work environment behavior and performance has become a serious issue in organizations spending billions of dollars annually on training and development (Baldwin \& Ford, 1988; Noe, 2010). Hence, the hotel sector needs to acknowledge the factors that impact training effectiveness and to determine those that promote or prevent changes in behavior to improve the training cost efficiencies (Noe \& Schmitt, 1986). To understand this phenomenon, this study intends to investigate the work environment, individual and training process as factors influencing the effectiveness of the training program conducted in the hotel sector.

\section{Literature review}

\section{Human Resource Training}

Training is considered as one of the major aspects in managing human resource since it will assist the organization to enhance the knowledge, skills and abilities of their employees (Rafiq, 2015). In fact, Sudhakar and Basariya (2017) believe that training is significant for giving a dynamic approach to organization as a parameter for enhancing the ability of workforce to achieve organizational objectives. Training plays a key role in ensuring that the staff is equipped with skills and knowledge required to deliver good customer services and is the main key to achieve success in hotel organizations (Tracy \& Tews, 1995). Training also drives every aspect of services to match guests' needs (Zhao, Junchuan \& Namasivayam, 2004). Further, training is also provided as an attempt to minimize the gap between guest expectations and hotel performance and training programs offers advantages for the hospitality organization and its employees (Chiang, Back \& Canter, 2005). Training is also used to educate the staff in order to enrich them with more commitment and loyalty (Jago \& Deery, 2002). Without this process, employees lack necessary skills and knowledge to carry the stress of work, which may result in their dissatisfaction (Cho, Woods, Jang \& Erdem, 2006; Jago \& Deery, 2002). Chaturvedi (2016) highlighted the importance of training program to hotels' employees in Faridabad, India as a way of invigorating new skills, building competency and propelling growth. Hence, assessing the application of real life training and measuring the change after the training is vital in remaining effectiveness of the program.

\section{The Effectiveness Of Training Program - Kirkpatrick Model}

The effectiveness of the training process refers to the training input factors, training outcomes and transfer conditions. According to Tannenbaum and Yukl (1992), training effectiveness is primarily determined through the trainees' attributes, pre-training and post-training environment, and the accuracy of the needs analysis and the training design's quality. The achievement of training effectiveness entails the organization's focus on three dimensions which are pieces forming the concept of effectiveness. These dimensions include; work environment that the participants are exposed to, individual factors of participants such as their features, and the training process such as training needs and the ways in which knowledge and skills are delivered to the participants.

Punia and Kant (2013) present several factors affecting training effectiveness and its implications for motivation, attitude, emotional intelligence, support from management and peers, training style and environment, open-mindedness of trainer, job related factors, self- 


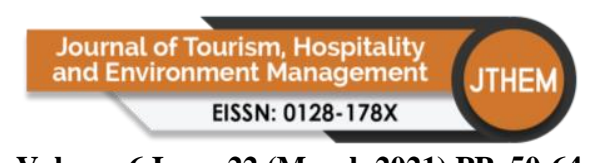

Volume 6 Issue 22 (March 2021) PP. 50-64

DOI 10/35631/JTHEM.622006

efficacy and basic ability. According to them, the management needs to assess the effectiveness of training program by gathering information related to the contributions of the training program to the organization, the needs to repeat and continue the program, and the ways to develop the training program. Yaqoot, Mohd. Noor and Mohd Isa (2017) utilized the Kirkpatrick model in their study to measure the antecedents of the training programs' effectiveness at public sector organizations in Bahrain. The Kirkpatrick's Four Level Evaluation Model has been widely accepted and considered useful in assessing training effectiveness (Cheng \& Ho, 1998). The study found positive relationships between the independent variables, trainer and social support toward training effectiveness.

The Kirkpatrick's Four Level Evaluation Model was introduced in 1976 by Donald L. Kirkpatrick and consisted of four consequence steps to evaluate the effectiveness of the training program (Kirkpatrick, 1976). The first step - reaction, measuring the feeling and emotions of the employees toward the training program. The second step - learning, measuring the outcomes of job performance based on the training program. The third step of the model behavior, investigating skills that have been developed during the training program. Finally the fourth step - results, explaining the contributions of the training program in achieving the organizational goals.

\section{Factors Influencing Training Program}

Sanjeevkumar and Yanan (2011) conducted a study regarding the factors influencing training program effectiveness involving employees of Kedah State Development Corporation Company. It focused on the types of training, training environment, work environment and employees' personal characteristics and noted that the training environment is the strongest driver of training effectiveness. In the hospitality perspectives, Atieno (2015) conducted a study regarding the factors influencing staff training and development in several hotels in Western Kenya. The study established that the major factors influencing staff training and development decisions in the State-Owned Hotels in western Kenya were the need to enhance productivity and improve performance, introduction of new approaches and processes to business and the need to match employee specifications with the job requirements and stake holders' needs.

Further, Luong (2015) conducted a study with fundamental purpose to identify and examine the factors affecting the effectiveness of training program in the micro and small enterprises. The factors were gathered into three groups namely the organizational factors, the management-related factors and the individual related factors. The research findings eventually revealed that the critical factors which significantly influence the training effectiveness are company's internal barriers, managerial support and training motivation. Additionally, a study by Siengthai, Boonkrob and Siengthai (2016) regarding the effectiveness of training program to the employees of Ministry of Interior, Thailand found that as a system, the training effectiveness is dependent on several factors such as the input into the training programs, namely, participant's and instructor's skills, knowledge and abilities, the training process itself which depends on the contents and methods used in the programs.

Mohd Shariff and AlMakhadmah (2012) investigated the work environment factors that influence the training programs' effectiveness in hotel sectors within the Aqaba Special Economic Zone Authority (ASEZA) and found that social support, opportunity to perform, reward system, and organization culture as the work environment factors influenced the 


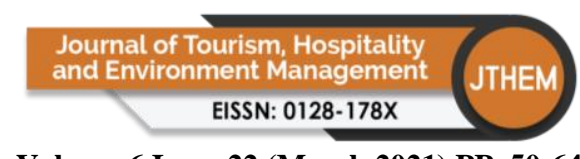

Volume 6 Issue 22 (March 2021) PP. 50-64

DOI 10/35631/JTHEM.622006

effectiveness of the training program. Amritharaj and Vembar (2014) in their study found that demographic and environmental factors also determined the effectiveness of training program in hotel industry. They conducted a study at hotels in Chennai City and suggested that hotels need to focus on these two aspects to improve the effectiveness of training program. Current study undertaken by El Hajjar and Alkhanaizi (2018) noted that the training contents, training environment, training facilities and materials, training schedule, and presentation style are important factors which needs to be focused by the stakeholders when evaluating any training programs to satisfy training effectiveness. In a current study, Alias, Ong, Rahim and Hassan (2019) found that the training design which consist of training content, training methods and trainer competency influenced the effectiveness of training program conducted among public service employees in Malaysia public training center. They also suggested that the training providers emphasize these factors in order to develop and implement training effectively.

\section{Research Methodology}

\section{Scope of The Study}

To investigate the factors influencing the effectiveness of training program for hotel employees, a well-established resort in Malaysia was selected as the scope of the study. The Datai Langkawi is a 5-star destination resort situated on the mystical island of Langkawi, Malaysia. The landscapes of the resort provide seamlessly nature rainforest adventure and experience to the guest. It offering breathtaking views through beautiful rooms, suites and villas with private verandahs. Well known as the best luxury hotel in the world, The Datai Langkawi has also won several awards for instance Best Hotel in the World in 2001, Best Luxury Hideaway Resort in Asia at the World Luxury Hotel Awards 2015 and ranked 27th on Readers' Travel Awards 2015 by Best Condé Nast Traveler (Nature at The Datai, 2018).

To meet the ever changing demand of upmarket travelers all over the world and stiffer competition, The Datai Langkawi has undergone an upgrading activities of its premise and management known as The Datai Invest in People Program (Overview Sdn. Bhd., 2017). The program is a holistic approach to upgrade and improve the existing staff's supervisory and management skills via a three prong approach of attitude alteration, skills development and knowledge enhancement. One of the important aspects which has been given attention by The Datai Langkawi' management is to provide a professional development program to the staffs in order to improve supervisory and management skills, increase economic efficiency, promote innovations, improve work processes and enhance productivity. Hence, a special program was developed by the appointed consultant, Overview Sdn. Bhd. and expertise from the School of Tourism, Hospitality and Event Management, Universiti Utara Malaysia named as - Executive Advance Certificate in Hospitality Management Program.

The program among others has been emphasized by the Overview Sdn. Bhd. to achieve several objectives for instance:

- $\quad$ To equip The Datai Langkawi's staffs with skills and knowledge in practical and theory needed to carry out management tasks and activities in the hotel industry;

- To provide a holistic approach in producing a well-rounded individual who are able to contribute to achieving the vision and mission of The Datai Langkawi;

- $\quad$ To produce professionals who are ethical, competent and able to compete in each

- To improve communication, intrapersonal and interpersonal skills and teamwork;

- To establish and elevate careers in the hotel and tourism industry; and 


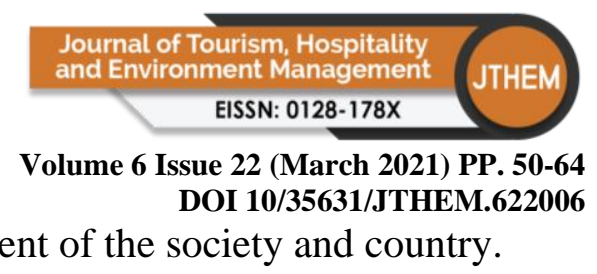

\section{Development of Hypotheses}

The study was a causal study to evaluate the factors influencing the effectiveness of training program. The independent variables referred to the three factors namely work environment, individual and training process. Additionally, the work environment were evaluated using four variables - social support, opportunity to perform, reward system and organizational culture. The individual factor was determined by individual ability, attitude and motivation. Finally, the training process consisted of the training needs analysis and the training design. As for the dependent variable of the study, it was measured by the effectiveness of training program which includes the reaction toward training process and level of learning the trainees obtain from training, the change in behavior and the development in performance which is applied on the job as a result of training program. Hence, several hypotheses were developed to answer the objectives:

H1: Work environment significantly influences the effectiveness of the training program.

H1-1: Social support significantly influences the effectiveness of the training program. H1-2: Opportunity to perform significantly influences the effectiveness of the training program.

H1-3: Reward system significantly influences the effectiveness of the training program. H1-4: Organizational culture significantly influences the effectiveness of the training program.

$\mathrm{H} 2$ : Individual factor significantly influences the effectiveness of the training program.

H2-1: Individual ability significantly influences the effectiveness of the training program.

H2-2: Individual attitude significantly influences the effectiveness of the training program.

H2-3: Individual motivation significantly influences the effectiveness of the training program.

H3: Training process significantly influences the effectiveness of the training program.

H3-1: Training needs significantly influence the effectiveness of the training program.

H3-2: Training design significantly influences the effectiveness of the training program. 


\section{Research Framework}

Based on the hypotheses, the study derived with a research framework as presented in Figure 1 .

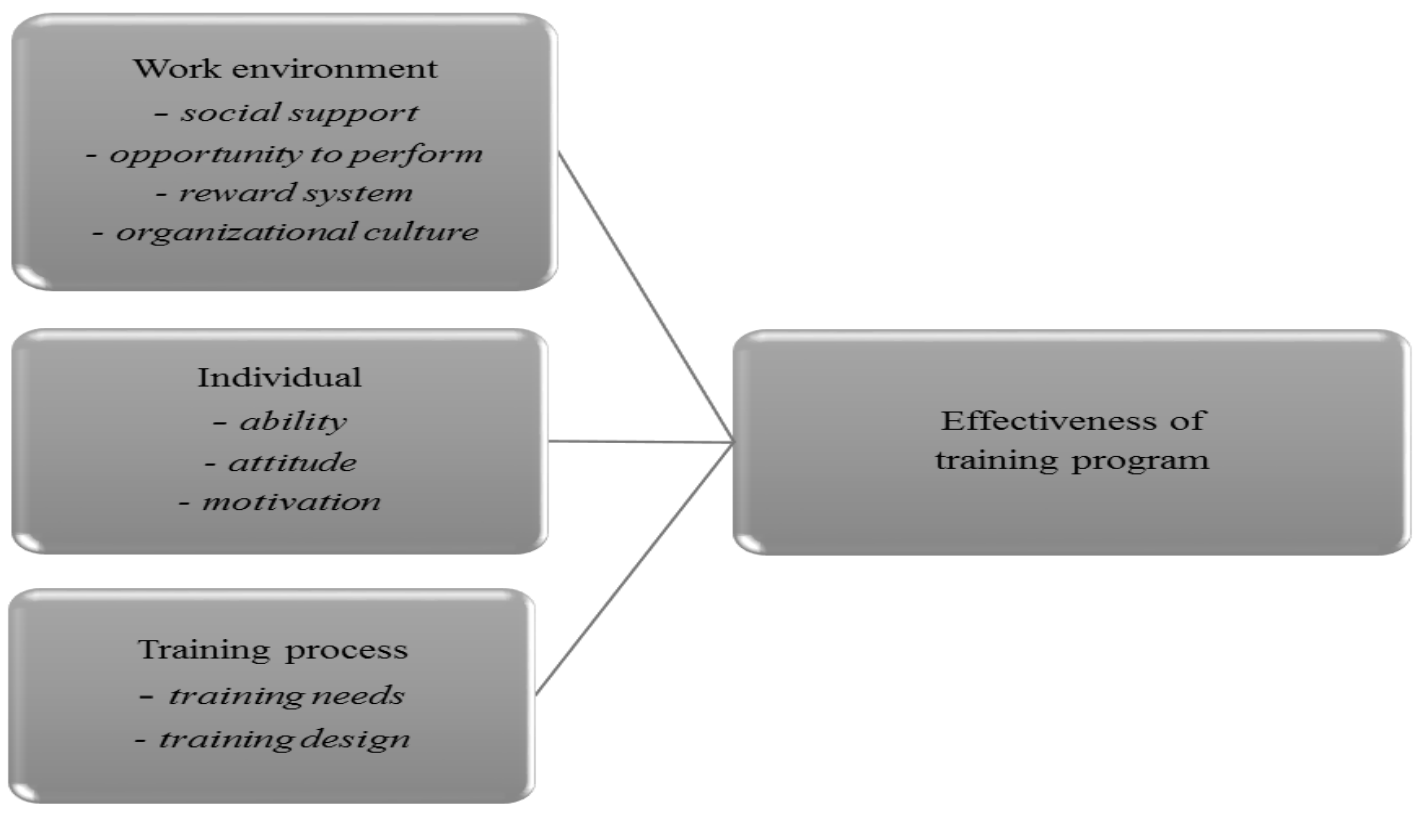

\section{Figure 1: Research Framework of the Study}

Source: Researcher' Own Study

\section{Instrumentation for The Study}

The study utilized a survey questionnaire in collecting the primary data from the respondents. 25 items were adopted and adapted from Kirkpatrick and Kirkpatrick (2007) based on the four levels evaluation training model. The items were tested for reliability and the findings indicated that all the three factors derived with high Cronbach's Alpha value. Table 1 depicts the number of items for the three factors and the analysis results of the reliability test.

Table 1: Number of Items in the Questionnaire and Reliability Test

\begin{tabular}{lcc}
\hline \multicolumn{1}{c}{ Independent Variables } & Items & $\begin{array}{c}\text { Cronbach's } \\
\text { Alpha }\end{array}$ \\
\hline Work Environment Factor & 3 & .905 \\
Social support & 4 & \\
Opportunity to perform & 3 & \\
Reward system & 4 & \\
Organizational culture & $\mathbf{1 4}$ & \\
Total & & .931 \\
Individual Factor & 4 & \\
Individual ability & 3 & \\
Individual attitude & 5 & \\
Individual motivation & $\mathbf{1 2}$ & \\
Total & & \\
Training Process Factor & 3 & \\
Need analysis & & \\
GLOBALACADEMIC EXCELLENCE $(M)$ SDN $B H D$ - All rights reserved &
\end{tabular}




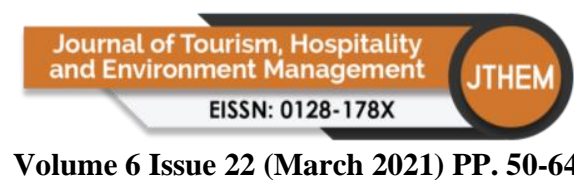

Volume 6 Issue 22 (March 2021) PP. 50-64

Training design

DOI 10/35631/JTHEM.622006

Total

Dependent Variable

Effectiveness of the training program

5

8

25

.956

Source: Researchers' Own Study

\section{Data Analysis}

The Datai Langkawi had conducted a special training program for its human resources in March 2018. 45 employees involved in the training program, hence the questionnaires were distributed to all the training participants. They were then analyzed using Statistical Package for Social Sciences (SPSS-PC) version16.0. The regression analysis was used to measure the influencing of the factors on the effectiveness of the training program. In statistics, regression analysis includes any techniques for modeling and analyzing several variables, when the focus is on the relationship between a dependent variable and one or more independent variables. More specifically, regression analysis helps one understand how the typical value of the dependent variable changes when any one of the independent variables is varied, while the other independent variables are held fixed. The $\mathrm{p}$ value was tested at 0.05 which indicated that if the probability of the test statistic is less than or equal to the probability of the alpha error rate, the null hypothesis is rejected.

\section{Findings}

\section{The Respondents' Background}

Table 2 depicts the findings regarding the respondents' background. Majority of the respondents are male (71.1 per cent) and the remaining are female (28.9 per cent). Most of them graduated from high school (62.2 per cent) and had diploma certificate (24.4 per cent). Few of them had finished their undergraduate $(6.7$ per cent) and postgraduate $(2.2$ per cent) studies. The findings also showed that most of them had been working between $6-10$ years ( 28.9 per cent), followed by between $16-20$ years ( 22.2 per cent) and above 21 years (10.0 per cent). As for the number of training program they had attended in a year, the findings of the survey revealed that majority of the respondents had attended less than five training programs in a year (73.3 per cent). Only few stated that they had attended more than 11 training programs in a year (11.1 per cent). Additionally, the findings of the survey indicated that majority of the respondents hold a supervisory post at the hotel (64.4 per cent), followed by the managerial post (22.2 per cent) and the remaining hold other positions (13.3 per cent).

Table 2: Respondents' Background ( $N=45)$

\begin{tabular}{|c|c|c|}
\hline Items & Frequency & $\begin{array}{c}\text { Percentage } \\
\%\end{array}$ \\
\hline \multicolumn{3}{|l|}{ Gender: } \\
\hline Male & 32 & 71.1 \\
\hline Female & 13 & 28.9 \\
\hline \multicolumn{3}{|l|}{ Education: } \\
\hline High school & 28 & 62.2 \\
\hline Diploma & 11 & 24.4 \\
\hline Undergraduate & 3 & 6.7 \\
\hline Postgraduate & 1 & 2.2 \\
\hline
\end{tabular}


Others

Number of years working:

Under 1 year

$1-5$ years

$6-10$ years

$11-15$ years

$16-20$ years

Above 21 years
Journal of Tourism, Hospitality

and Environment Management

EISSN: 0128-178X

Volume 6 Issue 22 (March 2021) PP. 50-64

DOI 10/35631/JTHEM.622006

Number of training attended in a

year:

Less than 5 times

6 - 10 times

More than 11 times

Position at the hotel:

Managerial 10

2

4.4

$\begin{array}{rr}1 & 2.2 \\ 7 & 15.6 \\ 13 & 28.9 \\ 5 & 11.1 \\ 10 & 22.2 \\ 9 & 10.0\end{array}$

Supervisory

29

33

73.3

15.6

11.1

5

22.2

Others

6

13.3

Source: Researchers' Own Study

\section{Work Environment Influences on The Effectiveness of Training Program}

The first hypotheses of the study proposed that the work environment significantly influences the effectiveness of the training program.

H1: Work environment significantly influences the effectiveness of the training program.

Four variables were used to measure the work environment namely, social support, opportunity to perform, reward system and organizational culture. Table 3 shows the findings of the regression analysis on work environment which includes the social support, opportunity to perform, reward system and organizational culture. The findings of the regression analysis indicated that all variables of work environment make a positive and significant contribution to the effectiveness of the training program. It can be seen that the opportunity to perform made the largest positive and significant contribution to the effectiveness of the training program (beta $=0.698 ; \mathrm{p}<0.000$ ). The total work environment showed significant contribution with a record of .669 and p value of .000. Hence, $\mathrm{H} 1$ is accepted. It can be concluded from the analysis that the work environment significantly influences the effectiveness of the training program.

Table 3: Hypotheses Findings of Work Environment Influences on the Effectiveness of Training Program

\begin{tabular}{lrr}
\hline \multicolumn{1}{c}{ Factors } & $\begin{array}{c}\text { Standardized } \\
\text { Coefficients Beta }\end{array}$ & $\begin{array}{c}\text { Sig. } \\
\text { (2-tailed) }\end{array}$ \\
\cline { 2 - 3 } Social support & $.644^{* *}$ & 0.000 \\
Opportunity to perform & $.698^{* *}$ & 0.000 \\
Reward system & $.390^{* *}$ & 0.000 \\
Organizational culture & $.498^{* *}$ & 0.000 \\
Total work environment & $.669^{* *}$ & 0.000 \\
\hline Source: Researchers' Own Study & &
\end{tabular}

Source: Researchers' Own Study 


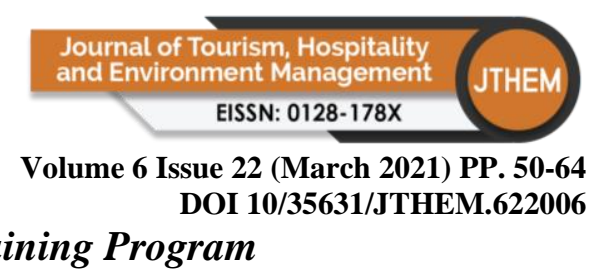

Individual Factor Influences on The Effectiveness of Training Program

The study also proposed that individual factor significantly influences the effectiveness of the training program.

H2: Individual factor significantly influences the effectiveness of the training program.

Three variables were used to measure the individual factors for instance, individual ability, individual attitude and individual motivation. Table 4 presents the findings of the regression analysis on the individual factor as an independent variable towards influencing the dependent variable of training program effectiveness. The findings indicated a positive and significant contribution of all the three variables. The total individual factor showed a significant contribution with a record of .723 and $p$ value of .000 . Hence, $\mathrm{H} 2$ is accepted and the findings concluded that individual factor significantly influences the effectiveness of the training program.

\section{Table 4: Hypotheses Findings of Individual Factor Influences on the Effectiveness of Training Program

\begin{tabular}{ccc}
\hline Factors & $\begin{array}{c}\text { Standardized } \\
\text { Coefficients Beta }\end{array}$ & $\begin{array}{c}\text { Sig. } \\
(2-t a i l e d)\end{array}$
\end{tabular}

\begin{tabular}{ccc}
\cline { 2 - 3 } Ability & $.735^{* *}$ & 0.000 \\
Attitude & $.694 * *$ & 0.000 \\
Motivation & $.582^{* *}$ & 0.000 \\
Total individual factor & $.723 * *$ & 0.000 \\
\hline
\end{tabular}

Source: Researchers' Own Study

\section{Training Process Influences on The Effectiveness of Training Program}

Further, the study proposed that the training process significantly influences the effectiveness of the training program.

H3: Training process significantly influences the effectiveness of the training program.

Two variables were used to measure the training process which are training needs and training design. As shown in Table 5, the findings of the regression analysis on the training process indicated a positive and significant contribution to the effectiveness of the training program. The total training process eventually showed a record of .654 and $p$ value of .000 , indicating a significant contribution. Additionally, the regression analysis on the training design indicated a positive and significant contribution which concluded that the training design significantly influences the effectiveness of the training program. However, the findings of regression analysis indicated a positive but somehow an insignificant contribution for the training needs with a record of .240 and $p$ value of .112. Hence, the proposed of training needs as an independent variable which may influence the effectiveness of the training program cannot be accepted. 


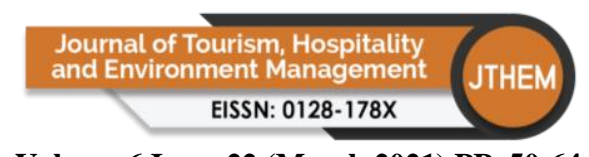

Volume 6 Issue 22 (March 2021) PP. 50-64

DOI 10/35631/JTHEM.622006

Table 5: Hypotheses Findings of Training Process Influences on the Effectiveness of Training Program

$\begin{array}{ccc}\text { Factors } & \begin{array}{c}\text { Standardized } \\ \text { Coefficients Beta }\end{array} & \begin{array}{c}\text { Sig. } \\ (2-\text {-tailed })\end{array}\end{array}$

\begin{tabular}{lll}
\cline { 2 - 3 } Training needs & $.606^{* *}$ & 0.000 \\
Training design & $.240^{* *}$ & 0.112 \\
Total training process factor & $.654^{* *}$ & 0.000 \\
\hline
\end{tabular}

Source: Researchers' Own Study

\section{Discussion}

Generally, the findings indicate that all the three factors significantly influence the effectiveness of the training program which eventually are in line to other previous studies (Mohd Shariff \& AlMakhmadmah, 2012; Sanjevkuman \& Yanan, 2011; Yaqoot, Mohd. Noor $\&$ Mohd Isa, 2017). The findings on the work environment significantly consistent to previous studies which also noted that social support and opportunity to perform as factors influencing the effectiveness of training program (El Hajjar \& Alkhanaizi, 2018; Lim, Lee and Nam, 2007; Mohd Shariff \& AlMakhadmah, 2012; Sanjevkumar \& Yanan, 2011; Tracey, Hinkin, Tannenbau \& Mathieu, 2001; Yaqoot, Mohd. Noor \& Mohd Isa, 2017).

The opportunity to perform is probably seen by the employees as a valuable aspect which is provided by the management including the provision of time and equipment which assists them to provide professional service to the guests. Additionally, the reward system is also as significant factor influencing the effectiveness of the training program and in line to previous studies such as Elangovan and Karakowsky (1999), Mohd Shariff and AlMakhadmah (2012), Rouiller and Goldstein (1993) and Tracey, Hinkin, Tannenbau and Mathieu (1995). Hence, the findings of the study probably show that the employees would be more encouraged to work harder when the management of the hotels would consider rewarding them continuously. However, there are few previous studies which indicated contradict findings to this current study on reward system. For instance Cheng and Ho (1998) and Xiao (1996) have noted in their studies that the reward system did not demonstrate significant influence on the training program.

The findings further indicate that organizational cultural influenced the training program which is similar to the previous studies by Burke and Baldwin (2012) and Tracey, Hinkin, Tannenbaum and Mathieu (1995). The findings would probably suggest that the employees recognize the organizational culture of the hotel and value the policies and strategies related to their tasks. In contrast, the findings did not support the findings by Mohd Shariff and AlMakhadmah (2012) where they noted that organizational culture of the hotel insignificantly influenced the effectiveness of training program for employees at Aqaba Special Economic Zone Authority ASEZA. Taking into account the individual element as factor influencing the training program of The Datai Langkawi, the findings are also consistent to previous studies which supported individual ability and attitude as factor influencing the effectiveness of the training program (El Hajjar \& Alkhanaizi, 2018; Luong, 2015; Mohd Shariff \& AlMakhadmah, 2012; Mathieu, Tannenbaum \& Salas, 1992, Tannenbaum \& Yuki, 1992 and Zhao, Junchuan \& Namasivayam, 2004). The employees of The Datai Langkawi probably perceived themselves as confident and committed to learn new skills which eventually lead to the success of the training program. 


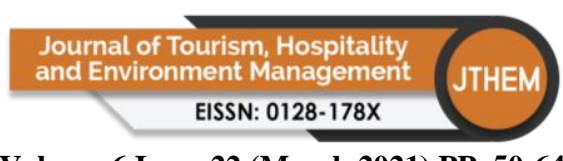

Volume 6 Issue 22 (March 2021) PP. 50-64 DOI 10/35631/JTHEM.622006

Further, they are also motivated to perform their tasks based on the new skills they gained from the training program. Hence, this reflects the findings on motivational aspect as factors influencing the effectiveness of the training program and consistent to the studies by Mathieu, Tannenbaum and Salas (1992) and Noe and Wilks (1992). The study has also examined the influence of the training process on the training program effectiveness. The training process derives as a significant factor influencing the effectiveness of the program, similar to the study by Yaqoot, Mohd. Noor and Mohd Isa (2017). This might be due to the fact that employees considered themselves as not in a position to evaluate the training process since it was prepared and designed by the expertise in the area. The findings further indicate that the training design is a significant factor influencing the effectiveness of training program which is in line to previous study such as by Alias, Ong, Rahim and Hassan (2019). Even though the training design indicates significant factor influencing the program, the other factors which the training needs show insignificant result. The employees probably find that they did not need the training program in the first place or maybe they would prefer to gain new skills through other activities and not through the training program. This findings are in contrast to other studies for instance Lim, Lee and Nam (2007) and Zhao, Junchuan and Namasivayam (2004) which found that training needs as the highest factor contributed to the effectiveness of training program.

\section{Implications, Limitations and Future Research}

The findings of this study would assist the stakeholders and management of The Datai Langkawi to understand the importance of having an effective training program to produce employees with efficient skills and knowledge to perform their tasks specifically relating to customer service. The challenge of achieving training program effectiveness is essential once they fully understand their roles in enhancing and increasing the training program effectiveness by taking into account those factors which may influence the program. Besides determining the success or failure of the training program, these factors may also contribute to strengthen the employees' relation specifically between the management and trainees. These factors would also contribute to the dimension of the effective training program in the form of enhancement in diagnostic works, work setting, and in light of barriers that may inhibit the application of trained skills and behavior changes of the employees.

Additionally, the knowledge of the factors influencing the training program could also assist the management of The Datai Langkawi to extend the efforts in the creation and facilitation of better conditions of practice in the hotel's operations. This can be achieved through the understanding of the activities in the work place, the knowledge, skills, and behavior that the staff must have in order to accomplish their work effectively. The training program conducted by the Overview Sdn. Bhd. eventually enhances The Datai Langkawi employees with competitive advantage of the hotel industry and at the same time ensures that the employees could apply their newly acquired skills in the work place.

However, the study is limited to the employees of The Datai Langkawi and the program developed only for the purpose of evaluating the hotel employees. Looking into the current findings concerning factors influencing the effectiveness of training program for the employees of The Datai Langkawi, it is recommended that several future studies should be conducted to confirm if the trend found in this study can be applied in other training programs. Further study should also be conducted to determine whether the trainees can maintain the learned skills and 


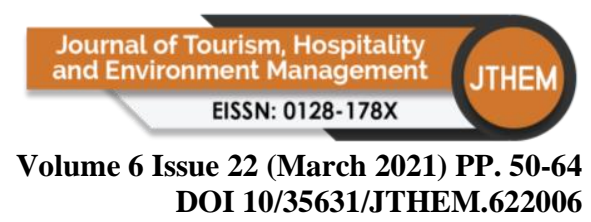

change behavior over time in a specific training program, which are conducted through longitudinal studies of training effectiveness.

Another study which compare the findings across times and assist the hotels in examining the findings should also be conducted to strengthen the existing findings from the literature. Additionally, it is suggested that future study to examine the influence of these factors on the demographic profiles of the employees such as age, educational level and their position at the hotel be undertaken. These variables are vital due to the fact they would determine the perceptions and behaviors of the employees toward the factors which may influence their evaluation regarding the training program. Other significant factors which are not included in this study for instance the management of the hotel, hotel's location and hotel's amenities should also be considered as they may also influence the effectiveness of the training program.

\section{Acknowledgements}

The researcher thanks the employees of The Datai Langkawi for participating in the study and the Overview Sdn. Bhd. for funding the study under the Agency Research Grant Scheme, Universiti Utara Malaysia, S/O Code 13990.

\section{References}

Alias, S.A., Ong, M.H.A., Rahim, A.R.A. \& Hassan, R. (2019). The role of training design factors in influencing training effectiveness among public service employees, International Journal of Academic Research in Business and Social Sciences, 9(5), 898913.

Amritharaj, S.M.D. \& Vembar, V. (2014). Demographic and environment factors influence on training and development effectiveness in hotel industry: a case study of selected hotels in Chennai, Journal of Human Resource Management and Labor Studies, 2(1), 83-95.

Atieno, J.I. (2015). Factors influencing staff training and development decisions in stateowned hotels in Western Kenya, A thesis submission for Master of Business Administration, University of Nairobi, Kenya.

Baldwin, T.T. \& Ford, J.K. (1988). Transfer of training: a review and directions for future research, Personnel Psychology, 41(1), 63-105.

Burke, L.A. \& Baldwin, T.T. (2012). Workforce training transfer: a study of the effect of relapse prevention in training and transfer climate, Human Resource Management, 38 (3), 227-241.

Chan Kim Lian, J., Che Sha'ari, S. \& Dasan, J. (2017). Exploring the factors influencing the employee career planning and development in star-rated hotels in Malaysia, Journal for Sustainable Tourism Development, 6(1), 49-60.

Chaturvedi, V. (2016). Investigating the factors affecting training decision among employees in hospitality industry (w.r.t. select categorized hotels in and around Faridabad), Amity Journal of Training and Development, 1(1), 77-92.

Cheng, W.L. \& Ho, C.K. (1998). The effects of some attitudinal and organizational factors on transfer outcome, Journal of Managerial Psychology, 13(5/6), 309- 317.

Chiang, C., Back, K. \& Canter, D. (2005). The impact of employee training on job satisfaction and intention to stay in the hotel industry, Journal of Human Resources in Hospitality and Tourism, 4(2), 99-118.

Cho, S., Woods, R.H, Jang, S.C. \& Erdem, M. (2006). Measuring the impact of human resource management practices on hospitality firms' performances, International Journal of Hospitality Management, 25(2), 262-277. 


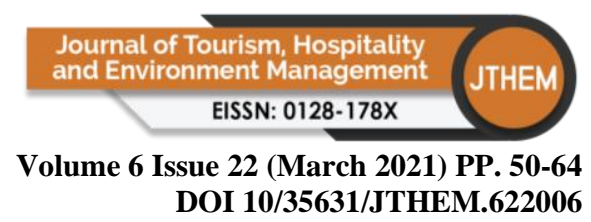

Clemenz, C.E. (2001). Measuring Perceived Quality of Training in the Hospitality Industry. Unpublished 3123749, Virginia Polytechnic Institute and State University, United States - Virginia.

Dardeer, M., Tag-Eldeen, A. \& Salem, I. (2018). The influence of physical work environment on hotel back-of-the-house employees' satisfaction and productivity: a case study on Hilton hotels, Review of Tourism Sciences, 18, 43-64.

Do, U. (2013). Improving the Effectiveness of Staff Training in A Hotel: Case Study Hotel X, Thesis submitted for Degree of International Business, Lahti University of Applied Science.

El Hajjar, S.T. \& Alkhanaizi, M.S. (2018). Exploring the Factors that Affect Employee Training Effectiveness: A Case Study in Bahrain. Sage Open, 1 - 12. DOI: 10.1177/2158244018783033. Retrieved from: www.journals.sagepub.com

Elangovan, A. \& Karakowsky, L. (1999). The role of trainee and environmental factors in transfer of training: an exploratory framework, Leadership \& Organization Development Journal, 20(5), 268-276.

Jago, L. \& Deery, M. (2002). The role of human resource practices in achieving quality enhancement and cost reduction: an investigation of volunteer use in tourism organisation, International Journal of Contemporary Hospitality Management, 14(5), 229-236.

Kirkpatrick, D.L. (1976). Evaluation of Training. In Craig, R.L. (Ed.) Training and Development Handbook: A Guide to Human Resource Development. McGraw Hill.

Kirkpatrick, D.L. \& Kirkpatrick, J.D. (2007). Implementing the Four Levels. CA: Berrett Koehler Publishers, San Francisco.

Lim, H., Lee, S. \& Nam, K. (2007). Validating e-learning factors affecting training effectiveness, International Journal of Information Management, 27(1), 22-35.

Luong, H. N. L. (2015). Factors Influencing Training Effectiveness in Micro and Small Enterprises - Case Service Oriented Company: Katrium $O$, Thesis submitted for Bachelor of International Business General Management. Turku University of Applied Science.

Masfar, Z. M. (2020). Exploring factors influencing employee turnover in Saudi Arabia's hospitality industry, American Journal of Tourism Management, 9(1), 1-18.

Mathieu, J., Tannenbaum, S. \& Salas, E. (1992). Influences of individual and situational characteristics on measures of training effectiveness, Academy of Management Journal, $35(4), 828-847$.

Mhlanga, O. (2018). Factors influencing employee motivation in hotels, African Journal of Hospitality, Tourism and Leisure, 7(3), 1-8.

Mohd Shariff, N. \& AlMakhadmah, I.M. (2012). Work environment factors influencing in achieving training effectiveness in Aqaba Special Economic Zone Authority ASEZA, Academic Research International, 2(3), 598-609.

Nature at The Datai (2018). Retrieved from https://www.thedatai.com

Noe, R. (2010). Employee Training and Development (Fifth Ed.). McGrow- Hill, Singapore.

Noe, R. \& Schmitt, N. (1986). The influence of trainee attitudes on training effectiveness: test of a model, Personnel Psychology, 39(3), 497-523.

Overview Sdn. Bhd. (2017). The Datai Invest in People Program. The OVSB-STHEM Executive Advance Certificate in Hospitality Management Program: A Proposal, pp. $1-21$. 


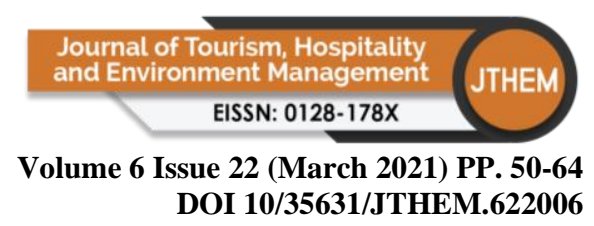

Punia, B.K. \& Kant, S. (2013). Review of factors affecting training effectiveness vis-à-vis managerial implications and future research directions, International Journal of Advanced Research in Management and Social Sciences, 2(1), 151-164.

Rafiq, M. (2015). Training evaluation in an organization using Kirkpatrick Model: A case study of PIA, European Journal of Business and Management, 7(25), 152-161.

Rouiller, J. \& Goldstein, I. (1993). The relationship between organizational transfer climate and positive transfer of training, Human Resource Development Quarterly, 4(4), 377 390.

Sanjeevkumar, V. \& Yanan, H. (2011). A study on training factors and its impact on training effectiveness in Kedah State Development Corporation, Kedah, Malaysia, International Journal of Human Resource Studies, 1(2), 136-156.

Siengthai, S., Boonkrob, D. \& Siengthai, M. (2016). Evaluation of training effectiveness: a case study of Ministry of Interior, Thailand, Comprehensive Research Journal of Management and Business Studies, 1(1), 7 -14.

Sudhakar, R. \& Basariya, S.R. (2017). Perspectives and the factors influencing the effectiveness of training and development on employees' performance, International Journal of Civil Engineering and Technology, 8(9), 135-141.

Tannenbaum, S.I. \& Yukl, G. (1992). Training and development in work organizations, Annual Review of Psychology, 43(1), 399-441.

Tracey, J.B. \& Tews, M.J. (1995). Training effectiveness: accounting for individual characteristics and the work environment, Cornell Hotel and Restaurant Administration Quarterly, 36(6), 36-42.

Tracey, J.B., Hinkin, T.R., Tannenbaum, S. \& Mathieu, J.E. (2001). The influence of individual characteristics and the work environment on varying levels of training outcomes, Human Resource Development Quarterly, 12(1), 5-23.

Xiao, J. (1996). The relationship between organizational factors and the transfer of training in the electronic industry in Shenzhen, China, Human Resource Development Quarterly, 7(1), 55-74.

Yaqoot, E.S.I., Mohd. Noor, W. \& Mohd Isa, M.F. (2017). Antecedents of training effectiveness in Bahrain, Expert Journal of Business and Management, 5(1), 13 -21.

Zhao, X., Junchuan, Z. \& Namasivayam, K. (2004). Factors affecting training success in China, Journal of Human Resources in Hospitality and Tourism, 3(1), 89-105. 